\title{
AS RECOMPENSAS JORDANIANAS ORIUNDAS DA ASSINATURA DO TRATADO DE PAZ COM ISRAEL (1994)
}

\section{Leonardo Luiz Silveira da Silva ${ }^{1}$}

Resumo: Em um mundo marcado pela intensificação dos transportes, comunicações e do comércio, as redes transnacionais colocam, ao lado do Estado, novos atores na política internacional. É este o contexto histórico-geográfico capaz de fazer rivais regionais que travaram duas guerras em um curto período de existência enquanto Estados-nação abandonarem a posição conflitiva e estabelecerem laços cooperativos. Este artigo objetiva apresentar os benefícios que motivaram a Jordânia a assinar o Tratado de Paz com Israel (1994), analisando o contexto internacional à luz dos pressupostos da Teoria da Interdependência Complexa. O exemplo tratado pelo artigo é extremamente didático, por apresentar um estudo centrado em rivalidades históricas regionais que se diluíram em meio à opção cooperativa, em um período emblemático, no início do pós-Guerra Fria. Tal período é notável devido intensificação dos fluxos transnacionais e intercontinentais, que são capazes, por sua vez, de colocar à prova os pressupostos da Teoria da Interdependência Complexa.

Palavras-Chave: Jordânia; Israel; Tratado de Paz; Interdependência Complexa.

\section{The Jordanian rewards deriving from the Peace Treaty with Israel (1994)}

\begin{abstract}
In a world marked by the intensification of transport, communications and commerce, trans national networks place new actors in international politics alongside the state. This is the historic geographical context capable of making regional rivals that have waged two wars in a short period of existence as nation-states abandon their conflictive position and establish cooperative ties. This article aims to present the benefits that motivated Jordan to sign the Peace Treaty with Israel (1994), analyzing the international context through assumptions of the Nye Jr. and Keohane's Complex Interdependence Theory. The example treated by the article is extremely didactic, for presenting a case study on regional historical rivalries that were diluted in the middle of the cooperative option, in an emblematic period, at the beginning of the post-Cold War. This period is notable due to the intensification of transnational and intercontinental flows, which in turn are able to test the assumptions of the Complex Interdependence Theory.
\end{abstract}

Keywords: Jordan; Israel; Peace treaty; Complex interdependence.

\footnotetext{
${ }^{1}$ Professor Efetivo do IFNMG-Campus Salinas. Rua Rio Pardo, 140, apto 102, Centro, Salinas, Minas Gerais, CEP 39560000. E-mail: leoluizbh@hotmail.com 


\section{INTRODUÇÃO}

O presente artigo trata de uma questão que vem, paulatinamente, emergindo no cenário global. Quais seriam as motivações para tradicionais rivais regionais passarem a adotar atitudes cooperativas e abandonar o amargor conflitivo que imperou desde a sua consolidação como Estados Nacionais? Para conseguirmos responder a esta questão, precisamos ir além das perspectivas trazidas pelo Realismo Político. Em um mundo caracterizado pelos 4 "Is" de Kenichi Ohmae (1999), o cenário político exige novas formas analíticas no campo da Geopolítica. Para o autor, os 4 "Is" que ajudaram a revolucionar as relações globais estão centrados no mercado de capitais que aumentam o fluxo financeiro transfronteiriço, a flexibilização produtiva da indústria, as possibilidades trazidas pela tecnologia da informação e a intensificação de um comportamento de consumo global por parte dos cidadãos. Neste cenário, as distâncias foram aniquiladas pelo tempo, denunciando a nossa condição pós-moderna, em uma paráfrase a David Harvey (2004). Deste modo, faz sentido insistirmos na geopolítica tradicional, firmemente abraçada aos pressupostos do Realismo Político?

Keohane e Nye Jr (2012) acreditam em um cenário em que algumas premissas do tradicional Realismo Político tenham perdido força. Ter-se-ia formado, neste cenário, uma nova condição ao qual os autores chamaram de Interdependência Complexa. A nova condição, construída pelas forças que intensificam a globalização e consolidam a ascensão de atores não-estatais na política mundial tornaria a possibilidade do uso da força militar, por parte dos Estados, menos provável. Partindo de lógica similar, Richard Rosecrance (1986) aposta que a força do comércio, por meio do aumento das relações entre membros da sociedade civil de países distintos, estaria colaborando para o aumento dos custos de um conflito militar, o que o tornaria menos provável. Pari Passu a este fenômeno estaria a expansão das democracias, como defende Francis Fukuyama (1992), que permitiram maior participação popular na gestão do governo, e, nas condições aqui alardeadas, seriam uma motivação a mais para as atitudes cooperativas prevalecerem.

Esta discussão parece atender ao estudo de caso das relações bilaterais entre Israel e Jordânia. Pa íses vizinhos que compartilham as águas da bacia do rio Jordão e que possuem importante minoria palestina em seus territórios, contava uma história mais conflitiva do que cooperativa. Os países em questão travaram duas guerras (Independência em $1948^{2}$ e dos Seis Dias em 1967) e tem como importante ponto de inflexão das suas relações bilaterais a assinatura do Tratado de Paz de 1994. O artigo tem como objetivo mostrar, sob o prisma da geopolítica jordaniana, a miríade de fatores que contribuiu, tal como em um jogo de múltiplas arenas (TSEBELIS, 1998) para a assinatura do Tratado de Paz do reino hashemita com Is rael. Para tanto, o artigo está estruturado em outras três partes além desta introdução. A primeira traz um breve histórico das relações conflitivas entre Israel e Jordânia. A segunda parte apresenta as forças que moveram a Jordânia e assinar 0 Tratado de Paz. A terceira e última parte traz as considerações finais.

\footnotetext{
${ }^{2}$ A Jordânia travou esta guerra sob o topônimo de Transjordânia. Estudos Geográficos, Rio Claro, 15(2): p-p, jul./dez. 2017 (ISSN 1678-698X) http://www.periodicos.rc.biblioteca.unesp.br/index.php/estgeo
} 


\section{BREVE HISTÓRICO DAS RELAÇÕES CONFLITIVAS ENTRE ISRAEL E JORDÂNIA}

Quando os britânicos deixaram definitivamente a região do Levante, em Maio de 1948, Egito, Transjordânia, Iraque, Síria, Líbano e Arábia Saudita entraram em Guerra contra o novo Estado de Israel. Mudanças territoriais profundas foram produzidas pelo confronto militar, que teve seus armistícios assinados durante o ano de 1949. O Estado árabe proposto pela partilha da ONU em 1947 deixou de existir a partir das conquistas territoriais de Israel e das anexações da Cisjordânia e da Faixa de Gaza, feitas respectivamente pela Jordânia e pelo Egito. A partir do armistício, a região desfrutou de relativa estabilidade nas suas fronteiras, que sofreriam mudanças significativas somente no conflito militar de 1967, conhecido como a Guerra dos Seis Dias.

A água era um elemento muito importante para a consolidação destes Estados, mas segundo Jagerskog (2003, p.80), trata-se de um exagero imaginar que somente a água tenha motivado estes pa íses recém criados a travarem a Guerra de Independência. Segundo o mesmo autor, a linha do armistício entre Israel e a Jordânia, que hoje é conhecida como linha verde, garantiu ao reino Hashemita a margem ocidental do rio Jordão (Cisjordânia). A posse da Cisjordânia garantia a Jordânia o acesso ao aquífero ocidental assim como boa parte do baixo rio Jordão, o que indicaria que a água não era a única prioridade dos sionistas.

Em Maio de 1950, as fronteiras originadas a partir do armistício entre Israel e seus vizinhos árabes foram endossadas pelos Estados Unidos, França e Inglaterra no documento que ficou conhecido como Declaração Tripartite. Com a estabilização das fronteiras através do armistício, Jordânia e Israel começaram a desenvolver projetos relativos à utilização dos recursos hídricos da bacia do rio Jordão. Contudo, a interpretação ambígua dos termos do armistício foi fonte de novas turbulências entre Israel e os seus vizinhos. De acordo com Lowi,

No início da década de 1950, tanto Israel quanto a Jordânia estavam engajados em formular e implementar unilateralmente seus planos de construção de uma política nacional em relação aos recursos hídricos, para desenvolver a capacidade de sua economia de absorver imigrantes e refugiados. Durante este período, aconteceram ações hostis e retaliações em áreas próximas às linhas de demarcação do armistício envolvendo Israel e seus vizinhos árabes. A área mais questionada era a do alto rio Jordão e a margem sudeste do lago Tiberíades (Kinneret). A discussão envolvia diferentes interpretações do status legal destas áreas. A Síria se opôs a eventuais planos israelenses de exploração ou desenvolvimento das áreas questionadas, enquanto a Jordânia, nação muito dependente das águas da bacia do rio Jordão, estava especialmente preocupada com a possibilidade de Israel desviar o fluxo da água a montante (LOWI, 1995, p.79-80).

Em 1952 Israel elaborou seu plano nacional para o abastecimento interno e desenvolvimento dos seus recursos hídricos, chamado de Plano dos Sete Anos (Seven Year Plan). Resumidamente, a ideia do plano consistia na construção de uma grande estrutura em rede que levaria a água de onde ela estivesse disponível até as áreas mais carentes do país (LOWI, 1995, p.49). Em termos práticos, isto 
significaria conduzir a água da bacia do Jordão até a planície costeira, área densamente povoada, assim como para o Negev, área mais carente de recursos hídricos do território israelense. Deste modo, a água da bacia do rio Jordão seria conduzida para áreas fora da bacia, o que contribuía para a deterioração das relações entre Israel e seus vizinhos árabes, pois estes últimos achavam que a água da bacia do rio Jordão somente deveria ser utilizada no interior da própria bacia.

Bastante pressionada no que diz respeito à relação entre disponibilidade e demanda de água, a Jordânia tinha nos projetos de desenvolvimento dos seus recursos hídricos a prioridade dentre os demais projetos nacionais. O reino Hashemita recebeu um grande fluxo de refugiados palestinos que estavam distribuídos, na década de 1950, na margem leste e oeste do rio Jordão (a margem oeste passou a ser controlada por Israel somente a partir de 1967). Ao mesmo tempo em que Israel desenvolvia os seus projetos hídricos à montante da bacia, a Jordânia passou a tratar com a Síria um acordo bilateral que viabilizaria a utilização conjunta do rio Yarmouk, principal tributário do rio Jordão. Segundo a ótica jordaniana, a construção de reservatórios era tida como viável do ponto de vista operacional, mas complicada politicamente, pois sugeria a cooperação entre os Estados recém-criados (SOSLAND, 2007, p.27). Contudo, na década de 1950 a cooperação não se mostrou opção razoável na visão dos governos árabes vizinhos a Israel, como argumenta Sosland particularmente no que tange a Jordânia:

Em 1952, o governo jordaniano, em conjunto com a Agência Técnica de Cooperação norte-americana e com a United Nations Relief and Works Agency (UNRWA), que foi estabelecida em 1949 para dar assistência aos refugiados palestinos, ofereceu uma nova sugestão, conhecida como plano Bunger, que evitava a cooperação com Israel. Esta proposta, que incorporava o assentamento de 100.000 refugiados palestinos no vale do rio Jordão, propunha o estoque das águas do rio Yarmouk através de um grande reservatório a montante deste tributário em Maqarin, servindo somente a Jordânia e a Síria. Ao contrário do plano de MacDonald ou lonides, o plano do reservatório de Maqarin tornou possível o fato de a Jordânia evitar a construção e utilização das águas de um reservatório na região do lago Kinneret, adiando uma eventual cooperação entre as partes (SOSLAND, 2007, p.28).

Em Junho de 1959, ao mesmo tempo em que a Jordânia anunciava seus projetos de desenvolvimento hídrico, Israel anunciou seus planos de começar a bombear a água do lago Kinneret para as regiões costeiras e para o Negev. Para completar a construção dos canais e das unidades de bombeamento essenciais para conduzir a água através da irregular topografia do seu território, Israel pediu financiamento aos Estados Unidos, sob o argumento de que, assim como o projeto jordaniano do Canal de East Ghor, o sistema National Water Carrier não iria retirar mais água do alto rio Jordão além daquela sugerida pela proposta não implementada de Eric Johnston (1955), negociador americano que falhou em meados da década de 1950 em costurar um acordo de cooperação hídrica entre os países da bacia do Rio Jordão (LOWI, 1995, p.118).

Assim que os detalhes a respeito do projeto israelense tornaram-se conhecidos, o Conselho da Liga Árabe resgatou o comitê técnico que havia sido formado na ocasião da missão de Eric Johnston pedindo uma avaliação a respeito Estudos Geográficos, Rio Claro, 15(2): p-p, jul./dez. 2017 (ISSN 1678-698X) 
do projeto israelense, recomendando uma ação internacional imediata contra o empreendimento. A mobilização das nações árabes não se mostrou suficiente porque:

\begin{abstract}
Apesar dos protestos dos árabes, Israel estava determinado a implementar o projeto: Moshe Dayan, forte candidato ao Knesset (parlamento israelense), anunciou em outubro de 1959 que o próximo governo de Israel iria levar as águas do Jordão para o Negev, com ou sem o consentimento dos árabes. Levi Eshkol, que seria o ministro das finanças do novo governo, declarou que o desvio das águas se tornou o projeto de prioridade máxima, sendo que o seu primeiro estágio seria finalizado em 1964 (LOWI, 1995, p.118).
\end{abstract}

A Jordânia, que é o país dentre os Estados árabes mais dependente das águas do rio Jordão fez um sério apelo para a adoção de uma ação conjunta para coibir a execução do projeto israelense. Duas ações possíveis foram cogitadas pelos árabes: o desvio das águas do rio Hasbani e do Banias para o Líbano e para a Síria, o que diminuiria o fluxo da água que abastece o lago Kinneret, ou o confronto militar. Encorajados pelo Egito de Nasser a não considerar naquele momento a segunda opção, sob a alegação de que os Estados Unidos estaria disposto a ajudar Israel caso o país sofresse uma agressão dos seus vizinhos árabes (LOWI, 1995, p.124), Síria e Líbano começaram a desviar as águas dos tributários do alto rio Jordão, em Dezembro de 1964. Além disto, planejavam construir um reservatório para impedir que as águas do Yarmouk chegassem a Israel (JAGERSKOG, 2003, p.85). Como reação a estas medidas por parte dos árabes,

Israel atacou as estruturas construídas para o desvio das águas do Hasbani e Banias diversas vezes entre os anos de 1965 e 1966, efetivamente interrompendo a construção. Estes incidentes são não raramente vistos como o prelúdio da guerra de 1967. Alguns argumentam que são parte de uma cadeia de eventos que conduziu Israel e seus vizinhos à guerra (JAGERSKOG, 2003, p.85).

Em 1967, a partir da hesitação das nações árabes aliadas em adotar a estratégia militar como resolução das questões pendentes com Israel, a força aérea israelense surpreendeu as nações aliadas ao lançar um ataque preventivo e arrasador à força aérea egípcia, importante aliado da Jordânia e da Síria. Entrando na guerra para apoiar o Egito, a Jordânia foi também derrotada com facilidade, perdendo toda a margem ocidental do rio Jordão (Cisjordânia) sob o seu controle. O Egito perdeu a Faixa de Gaza e a Península do Sinai, enquanto a Síria, que também participou dos combates contra as tropas israelenses, perdeu as colinas de Golã. Após a Guerra, Israel passou a ter controle sobre $42 \%$ da área de drenagem da bacia do rio Jordão, contra 25\% que tinha antes de 1967 (JAGERSKOG, 2003, p.85). Além disto, passou a controlar as nascentes do alto rio Jordão, que os seus vizinhos árabes ameaçavam desviar. Dos três países árabes co-usuários da bacia, o reino da Jordânia foi o que sofreu as piores perdas. Segundo Lowi,

Ao perder a Cisjordânia, a Jordânia perdeu 1/3 de sua população e a melhor porção de terra do seu território no que diz respeito ao 
potencial agrícola. Apesar da Cisjordânia corresponder a somente $6 \%$ da área total do reino, ela colaborava com cerca de $45 \%$ de todo o Produto Interno Bruto do país em 1966, um quarto de toda a sua terra cultivada e $60 \%$ de toda a sua produção agrícola. A Jordânia também perdeu Jerusalém Oriental, que não era somente um símbolo religioso, mas também uma região com grande potencial turístico. Além destas perdas, recebeu cerca de 300.000 refugiados palestinos adicionais vindos da Cisjordânia e da Faixa de Gaza (LOWI, 1995, p.149).

Após a Guerra dos Seis Dias (1967), a Jordânia optou por não se envolver diretamente em outros conflitos militares contra Israel. O Egito, grande liderança árabe regional e berço do pan-arabismo, assinou a paz com Israel na virada da década de 1970-80. Como o Egito era, dentre os vizinhos árabes de Israel, a nação econômica e militarmente mais capaz, a assinatura representou uma mudança no comportamento da Síria e da Jordânia em relação à Israel, arrefecendo sua disposição de adotar a alternativa militar para fazer valer os termos da resolução $242^{3}$ do Conselho de Segurança da ONU (1967). A Jordânia abandonou definitivamente o posicionamento político anterior, definido por Dona Stewart como: "a oposição a Israel, sempre ao lado dos árabes, não importa o quanto isto lhe custe" (STEWART, 2007, p.17). Mesmo durante períodos de guerra, a proximidade geográfica forçou Jordânia e Israel a adotarem uma série de medidas conjuntas que acabaram sendo os pilares para um acordo futuro mais amplo. Ao longo dos anos 1970, mesmo que secretamente, Israel e Jordânia já tratavam de questões bilaterais.

\section{AS FORÇAS QUE MOVERAM A JORDANIA À PAZ}

A conclusão da paz entre Egito e Israel contribuiu de forma significativa para que a Jordânia pudesse avançar seus entendimentos com Israel, livre de maiores constrangimentos frente ao mundo árabe, apesar de os acordos com Israel não serem uma unanimidade entre os habitantes do Egito e da Jordânia.

Os anos 1970 e notadamente 1980 foram caracterizados pelo aumento das reivindicações de natureza nacionalista por parte dos palestinos da Cisjordânia. A conclusão da paz entre Egito e Israel colocou os palestinos em uma difícil posição no que diz respeito ao seu relacionamento com o governo israelense. Esta posição desconfortável se consolidou à medida que não houve nação que se aventurasse militarmente contra Israel após o Tratado de Paz de 1979 (Egito e Israel), o que permitiria as lideranças palestinas projetar um Estado próprio mediante uma eventual derrota militar de Israel no Oriente Médio. A Cisjordânia, que pertencia a Jordânia antes da Guerra dos Seis Dias, serviu como mais um passo para a aproximação de Israel e a Jordânia quando,

Por volta de 1988, esforços para a resolução do conflito político com a OLP, e o alcance de uma solução que combinaria os objetivos do nacionalismo palestino e o papel da Jordânia no território, claramente falharam. Além disto, a situação da Cisjordânia, envolvida na primeira intifada palestina, causou crescente tensão entre a

\footnotetext{
${ }^{3}$ Que exigia a composição dos limites territoriais de acordo com o status quo ante bellum. Estudos Geográficos, Rio Claro, 15(2): p-p, ju 1./dez. 2017 (ISSN 1678-698X) 
população palestina da Jordânia e o governo Hashemita. Dentro deste contexto, a monarquia Hashemita desengajou-se da Cisjordânia e formalmente renunciou à reivindicação deste território em 31 de Julho de 1988 (STEWART, 2007, p.20).

Apesar destas forças a favor da aproximação da Jordânia, a conturbada política do Oriente Médio trouxe, na ocasião da Guerra do Golfo, um revés neste percurso para a construção de uma imagem positiva do país frente a Israel e ao mundo ocidental. O Iraque, que havia demonstrado suas intenções expansionistas durante a guerra contra o Irã (1980-1988), invadiu o Kuwait em 1990. A invasão do Kuwait pelo regime de Saddam Hussein não foi tolerada pelo Ocidente. A Jordânia encontrava-se a partir disto em uma posição política desconfortável à medida que o Iraque era no início da década de 1990, um dos principais parceiros comerciais do reino, sendo inclusive o principal fornecedor de petróleo para o governo de Amã. Ao contrário da Guerra do Iraque em 2003, muitos países árabes, incluindo Egito, Síria e Arábia Saudita, abertamente se juntaram a coalizão que combateu as tropas iraquianas no Kuwait. A Jordânia teve seus motivos para permanecer na neutralidade nesta ocasião:

Esta posição permitiu que a Jordânia atendesse a questões internas, como por exemplo uma parte importante da população queria que o governo lutasse ao lado do Iraque. É importante lembrar que os objetivos da Guerra do Golfo eram bem mais limitados do que a Guerra contra o Iraque em 2003. A queda do regime de Saddam Hussein não era esperada, o que significava que a Jordânia pudesse continuar fazendo acordos com o Iraque após o fim da ação militar na região (STEWART, 2007, p.23).

Os Estados Unidos e os seus aliados não apreciaram o posicionamento político da Jordânia, que era percebido como pró-Iraque e não raramente descrito como o mais próximo aliado do Iraque (STEWART, 2007, p.23). O impacto econômico do posicionamento político da Jordânia durante a Guerra do Golfo foi muito severo. A Jordânia perdeu dinheiro de diversas fontes como uma retaliação pela neutralidade:

Os Estados Unidos imediatamente cancelou 35 milhões de dólares de ajuda econômica e 20 milhões de ajuda militar na intenção de punir o rei Hussein por aquilo que os americanos perceberam como apoio a Saddam Hussein. Ácaba, o único porto da Jordânia, foi proibido de fazer trocas comerciais com o Iraque, o que pesou sobre as exportações da Jordânia como um todo. Além do mais, os Estados do Golfo congelaram as transferências de um montante de 1,6 bilhões de dólares; 200.000 trabalhadores de nacionalidade jordaniana retornaram para casa vindos do Golfo, com a perda de 150 a 300 milhões de dólares de remessas somente do Kuwait. O desemprego atingiu 25 a 30\%, enquanto a renda per capita diminuiu 13 a $14 \%$. Somado a isto tudo, o Estado lutou para lidar com um montante de 8,4 bilhões de dólares de dívida externa. (STEWART, 2007, p.23) 
Este comportamento recalcitrante da Jordânia durante a Guerra do Golfo, desalinhado das ações políticas que permearam a política externa do reino nas últimas duas décadas serviram para proporcionar o alinhamento do país com as políticas de interesse norte-americano. Logo após o fim da Guerra do Golfo, a Jordânia estava isolada regionalmente e internacionalmente. Na visão de Stewart (2007), as ações norte-americanas na Guerra do Golfo, ocorridas na intenção de proteger o Kuwait, provavelmente tornaram mais fácil a decisão do rei Hussein de fazer a paz com Israel, a partir do pressuposto que a Jordânia, assim como Israel, poderia ser protegida pelos Estados Unidos na ocasião de alguma hostilidade. Outro fator muito relevante foi o econômico: Clinton prometeu perdoar 700 milhões de dólares de dívida externa e pressionar líderes ocidentais a fazerem o mesmo (STEWART, 2007, p.24).

A participação do reino Hashemita na Conferência de Madrid (1991), cujo objetivo ser-se-ia aproximar Israel dos seus vizinhos árabes, foi importante para a reconstrução da imagem da Jordânia frente ao ocidente. A delegação palestina, incluída na delegação jordaniana, também tratou com Israel importantes assuntos considerados como o ponto de partida para a consolidação dos Acordos de Oslo (entre palestinos e israelenses) e para a assinatura do Tratado de Paz entre Jordânia e Israel.

O Tratado de Paz entre Jordânia e Israel foi concluído no meio da euforia causada pelos Acordos de Oslo, em um momento em que a região acreditou que a resolução de décadas de conflito entre palestinos e israelenses estava próxima. É preciso estabelecer um vínculo entre a questão palestina e a relação bilateral entre Jordânia e Israel, como deixa claro Stewart (2007):

Enquanto é enganoso acreditar que o governo da Jordânia e a área das relações sociais estão sempre de acordo com os objetivos dos palestinos, a relação jordaniana-israelense está intimamente ligada ao estado das relações entre israelenses e palestinos (...)

(...) Com a maior parte de sua população composta por palestinos (muitos dos quais carregam nacionalidade jordaniana), a maior parte dos jordanianos tem conexões familiares com os Territórios Ocupados, e a política israelense diretamente afeta suas famílias e seus amigos. (STEWART, 2007, p.10).

$\mathrm{Na}$ arena política, têm-se duas situações distintas no que se refere ao apoio ao Tratado de Paz. No Knesset (parlamento israelense) o Tratado foi aprovado por ampla maioria: 105 votos favoráveis e 3 contrários. Já na câmara dos deputados da Jordânia, a votação foi mais apertada: 55 votos favoráveis e 23 contrários (STEWART, 2007, p.25). A oposição interna da Jordânia ao Tratado, mais significativa no âmbito do parlamento do que em Israel, transformou os supostos benefícios econômicos do acordo em uma verdadeira bandeira do marketing do governo para a população. Na Jordânia, a oposição estava centrada nos grupos Islâmicos e nos partidos de tendência esquerdista.

O Tratado de Paz entre Israel e a Jordânia conta com um preâmbulo, trinta artigos e três anexos, um dos quais trata das "questões relacionadas à água". 0 quadro 1 a seguir apresenta os assuntos abordados nos artigos e nos anexos: 
As recompensas jordanianas...

QUADRO 1 - Estrutura detalhada do Tratado de Paz entre Israel e a Jordânia de 1994

\begin{tabular}{|c|c|}
\hline Item & Assunto abordado \\
\hline Artigo 1 & Estabelecimento da Paz \\
\hline Artigo 2 & Princípios Gerais \\
\hline Artigo 3 & Fronteira Internacional \\
\hline Artigo 4 & Segurança \\
\hline Artigo 5 & $\begin{array}{l}\text { Relações diplomáticas e outras relações } \\
\text { bilaterais }\end{array}$ \\
\hline Artigo 6 & Água \\
\hline Artigo 7 & Relações econômicas \\
\hline Artigo 8 & Pessoas refugiadas e desalojadas \\
\hline Artigo 9 & Lugares de significância histórica e religiosa \\
\hline Artigo 10 & Trocas culturais e científicas \\
\hline Artigo 11 & $\begin{array}{l}\text { O entendimento mútuo e relações de } \\
\text { vizinhança }\end{array}$ \\
\hline Artigo 12 & O combate ao crime e às drogas \\
\hline Artigo 13 & Trans porte \\
\hline Artigo 14 & $\begin{array}{l}\text { Liberdade de navegação e acesso aos } \\
\text { portos }\end{array}$ \\
\hline Artigo 15 & Aviação civil \\
\hline Artigo 16 & Correio e Telecomunicações \\
\hline Artigo 17 & Turismo \\
\hline Artigo 18 & Meio Ambiente \\
\hline Artigo 19 & Energia \\
\hline Artigo 20 & O desenvolvimento do Rift Valley \\
\hline Artigo 21 & Saúde \\
\hline Artigo 22 & Agricultura \\
\hline Artigo 23 & Aqaba e Eilat \\
\hline Artigo 24 & Reivindicações \\
\hline Artigo 25 & Direitos e Obrigações \\
\hline Artigo 26 & Legislação \\
\hline Artigo 27 & Ratificação \\
\hline Artigo 28 & Medidas provisórias \\
\hline Artigo 29 & Resolução de litígios \\
\hline Artigo 30 & Registro \\
\hline Anexo I & $\begin{array}{l}\text { A demarcação da fronteira internacional } \\
\text { entre Jordânia e Israel }\end{array}$ \\
\hline Anexo II & Questões associadas à água \\
\hline Anexo III & Combate ao crime e às drogas \\
\hline
\end{tabular}

Fonte: Autoria própria

Estudos Geográficos, Rio Claro, 15(2): p-p, ju 1./dez. 2017 (ISSN 1678-698X)

http://www.periodicos.rc.biblioteca.unesp.br/index.php/estgeo 
Além de todo o contexto histórico já abordado, existem questões pontuais que tornar-se-iam grandes motivadores para que a Jordânia assinasse o acordo de paz com Israel. Os fatores estão dispostos e discutidos a seguir:

A) A disputa pelos recursos hídricos da bacia do rio Jordão: $O$ anexo II (que aborda a questão dos recursos hídricos) do Tratado de Paz entre a Jordânia e Israel é, ao lado do Anexo que trata da demarcação das fronteiras, o mais detalhado item do documento. Apesar do fato da água ser um bem comum sugerir que ela deva ser compartilhada, o Tratado de Paz entre Israel e Jordânia favoreceu, na opinião de analistas como Stewart, a Jordânia, apesar da superioridade econômico-militar israelense e do fato de Israel ser também carente de recursos hídricos. Conforme já foi visto, o acordo sobre os recursos hídricos resultou em um imediato incremento líquido no abastecimento de água para a Jordânia, juntamente com o compromisso de uma busca em conjunto para o aumento do abastecimento por intermédio do processo de dessalinização (STEWART, 2007, p.55). Tanto Israel quanto a Jordânia reconhecem no terceiro parágrafo do sexto artigo do Tratado de Paz que os seus recursos hídricos não são suficientes para atender a sua demanda. Apesar disto, Israel concordou em permitir o incremento do abastecimento de água da Jordânia, mesmo que não fosse muito expressivo, em detrimento do seu aumento.

B) O turismo: este foi um dos setores que melhor reagiu mediante a formalização do Tratado de Paz entre Israel e Jordânia. Em 1995, as receitas do turismo atingiram um recorde de 723 milhões de dólares, o que correspondia a $15 \%$ do Produto Interno Bruto do ano. Turistas de Israel passaram a viajar em um grande número para a Jordânia: de quase zero visitante em 1994 para 100.079 nos últimos dez meses de 1995 (STEWART, 2007 p.91). Apesar dos turistas israelenses representarem cerca de $9 \%$ do total de visitantes em 1995, este número tenderia a crescer devido à finalização do acordo sobre o transporte entre os dois Estados. A formalização do Acordo de Paz também trouxe impressão de mais segurança ao turista estrangeiro. A cooperação envolvendo Israel e Jordânia potencializa uma área caracterizada pelo turismo religioso:

Não somente os visitantes israelenses passaram a chegar em grandes números como também os norte-americanos e europeus, envolvidos com os tours na Terra Santa originários em Israel, poderiam continuar o seu passeio na Jordânia. Com várias atrações turísticas incluindo a famosa cidade de Petra dos Nabateus, locais religiosos cristãos como o Monte Nebo e praias do Mar Vermelho, a Jordânia via a paz como um meio de capitalizar amplamente seus vastos recursos do turismo (STEWART, 2007, p. 91).

A melhoria do turismo a partir da formalização do tratado fica evidenciada pelo aumento no número de hotéis, quartos e camas disponíveis, que cresceu ano após ano desde 1994 (tabela 1). É importante ressaltar que o setor é muito sensível à instabilidade política. Mesmo com o aumento da violência em dados momentos do período pós-Tratado de Paz, o turismo continuou crescendo, mas aquém das suas possibilidades. Em períodos turbulentos como no biênio 2000-2001, marcado pela Segunda Intifada Palestina e pelos Atentados Terroristas de 11 de Setembro em Nova York, o número de turistas americanos, europeus e do Leste Asiático diminuíram significativamente. A entrada de turistas americanos que foi de 126.411 
em 2000, caiu para 74.568 no ano seguinte. Com os turistas europeus algo semelhante foi detectado: de 326.574 em 2000 para 207.332 em 2001. Apesar de tudo, mesmo nos períodos violentos e instáveis politicamente, o número dos turistas árabes continuou a crescer, sendo que em 2002 o número total de turistas na Jordânia foi quase o dobro do registrado em 1994, como registra a tabela 2.

TABELA 1 - Hotéis Jordanianos/ Capacidade hoteleira, 1994-2002

\begin{tabular}{lrrrrrrr}
\hline Estrutura & 1994 & 1995 & 1997 & 1999 & 2000 & 2001 & 2002 \\
\hline Hotéis & 129 & 148 & 175 & 247 & 278 & 298 & 309 \\
Quartos & 7250 & 8565 & 10147 & 13781 & 15091 & 16880 & 17400 \\
Camas & 13692 & 16093 & 19074 & 26295 & 29002 & 32001 & 32658 \\
\hline \multicolumn{7}{c}{ Fonte: STEWART (2007) }
\end{tabular}

A partir dos fatos de que o turismo corresponde a uma importante fatia do PIB jordaniano e de que o setor é bastante sensível às instabilidades políticas, é plausível admitir que a normalização das relações bilaterais entre Jordânia e Israel, assim como entre palestinos e israelenses e, de forma mais ampla, a construção de um ambiente político mais estável em todo o Oriente Médio, são condições sine qua non para a maximização das receitas e da exploração das possibilidades do turismo na região.

TABELA 2 -Turistas recebidos na Jordânia, 1994-2002 em mil

\begin{tabular}{|c|c|c|c|c|c|c|c|}
\hline $\begin{array}{c}\text { Origem dos } \\
\text { Turistas }\end{array}$ & 1994 & 1995 & 1997 & 1999 & 2000 & 2001 & 2002 \\
\hline $\begin{array}{l}\text { Países } \\
\text { Americanos }\end{array}$ & 69,8 & 103,3 & 107,6 & 123,5 & 126,4 & 74,5 & 72,9 \\
\hline $\begin{array}{l}\text { Países } \\
\text { Europeus }\end{array}$ & 192,1 & 255,4 & 239,4 & 292,7 & 326,5 & 207,3 & 167,1 \\
\hline $\begin{array}{l}\text { Leste } \\
\text { Asiático e } \\
\text { Pacífico }\end{array}$ & 30,9 & 45,7 & 47,8 & 51,6 & 59,9 & 41,9 & 73,8 \\
\hline $\begin{array}{l}\text { África e } \\
\text { países não- } \\
\text { árabes }\end{array}$ & 0,7 & 2,3 & 2,3 & 2,8 & 6,3 & 4,5 & 5,4 \\
\hline $\begin{array}{l}\text { Países } \\
\text { Árabes }\end{array}$ & 553 & 566,5 & 604,1 & 761,5 & 770,7 & 963 & 1131,2 \\
\hline Israel & 10,7 & 100 & 125,1 & 125,5 & 136,7 & 186,2 & 161,7 \\
\hline Total & 857,6 & 1073,5 & 1127 & 1357,8 & 1426,8 & 1477,6 & 1612,4 \\
\hline
\end{tabular}

Fonte: STEWART (2007) 
C) A Questão Palestina: o fato de Israel ocupar a Cisjordânia, território-chave na reivindicação palestina, e ter ocupado a Faixa de Gaza durante décadas, impondo a sua força militar sobre este território, tornar-se-iam o país intimamente ligado à causa palestina. Quando Israel ocupou a Cisjordânia em 1967, na ocasião da Guerra dos Seis Dias, a Organização para a Libertação da Palestina (OLP) passou a utilizar a Jordânia como base para o desenvolvimento de sua capacidade militar e realização de ataques sistemáticos a Israel. A falta de controle do governo jordaniano sobre as ações dos palestinos na região fronteiriça entre a Jordânia e o então território recém-anexado da Cisjordânia colocava em risco a soberania do reino.

\begin{abstract}
A escalada de eventos na Jordânia entre 1968 e 1969 culminou no seqüestro de cinco aeronaves pela Frente Popular de Libertação da Palestina, que foram forçadas a aterrissar na Jordânia precipitando um embate entre o Rei Hussein e as facções palestinas pelo controle do reino em Setembro de 1970. Em meio a uma guerra civil de grande escala, conhecida como Setembro Negro, a monarquia convocou as forças armadas para combater os palestinos que declararam parte do norte da Jordânia como área palestina livre. $O$ embate que se desenvolveu teve a participação de tanques, artilharia e força aérea (...)

(...) Após o Setembro Negro, a Jordânia expulsou toda a OLP do seu país e fechou os seus escritórios. O Conflito entre palestinos e jordanianos não terminou aí: em Novembro de 1971, o Primeiro Ministro jordaniano, Wasfi Tell, foi alvejado por disparos no Cairo, por criminosos que procuravam vingança pelo seu papel no desmantelamento das guerrilhas palestinas da Jordânia no Setembro Negro (STEWART, 2007, p. 19-20).
\end{abstract}

A presença de palestinos na Jordânia representa, desde o episódio do Setembro Negro, a possibilidade de um levante contra a monarquia Hashemita. Além disso, o princípio da inviolabilidade do território jordaniano, pressuposto básico de uma nação soberana, foi colocado em xeque pelas invasões do território do país, feitas por Israel, justificadas pela busca de militantes palestinos. Um dos maiores exemplos do afronto à soberania jordaniana foi o bombardeio no vale do Rio Jordão em uma vila utilizada pela facção palestina dos fedayin (STEWART, 2007. p.27).

Além disso, enquanto a criação de um Estado Palestino na Cisjordânia não se concretiza, as agressões israelenses e o sofrimento da população palestina deste território ocupado são convites à migração deste povo para o território jordaniano, onde muitos já habitam. Para um país pobre em recursos energéticos e hídricos, importador de comida, dotado de déficit crônico na balança comercial e carente de ajuda internacional, a migração palestina representa um peso ainda maior na sua economia. Este argumento endossa a percepção de que existe uma forte ligação entre os Acordos de Oslo e a formalização do Tratado de Paz entre Israel e Jordânia. Os Acordos de Oslo pareceriam ser, como já foi dito, o passo inicial para a resolução da Questão Palestina. A criação de um Estado Palestino aliviaria diversas tensões (de natureza demográfica e política) que rondam o Estado jordaniano.

Shimon Peres, influente político israelense, declarou em sua autobiografia que enquanto os israelenses estavam negociando os Acordos de Oslo, não estavam somente motivados pelos seus interesses diretos relacionados com a segurança, 
mas também os interesses jordanianos (STEWART, 2007, p.29). O desenvolvimento de relações mais próximas de Israel com a Jordânia possibilitou a ampliação da cooperação na questão da segurança. Tanto Israel e Jordânia, possuem preocupações conjuntas no que diz respeito aos palestinos e a seus respectivos Estados.

Tanto a Jordânia quanto Israel estão de acordo que o território jordaniano pode ser utilizado por grupos radicais da região para ataques sistemáticos, inclusive com mísseis, a Israel. Por esta razão a cooperação de segurança geralmente é muito estreita, o que inclui a existência de um escritório do Mossad em Amã, no intuito de compartilhar informação sobre grupos extremistas que estão em operação na região (STEWART, 2007, p.35)

Apesar de relações tão próximas no que diz respeito à cooperação envolvendo questões de segurança, a Jordânia experimenta no nível popular um descontentamento pela presença do Mossad em Amã, agravado pela tentativa de assassinato de Khalid Meshal, político palestino e um dos dirigentes do Hamas, considerado um dos principais arrecadadores de fundos para o grupo. Quando Meshal estava em Amã em Setembro de 1997, dois agentes israelenses do Mossad, que portavam passaportes canadenses, tentaram envenená-lo, o que foi entendido como uma flagrante violação da soberania jordaniana. Com a insistência do rei Hussein, Israel forneceu o antídoto que salvou a vida de Meshal (STEWART, 2007, p.47).

Este episódio gerou forte inquietação popular na Jordânia. O governo do país, que prendeu os dois agentes do Mossad responsáveis pelo atentado, ofereceu a soltura dos prisioneiros israelenses pela liberdade do líder espiritual do Hamas, Ahmed Yassin, dentre outros setenta prisioneiros palestinos e jordanianos que estavam em prisões israelenses. Era uma ação estratégica na tentativa de reconstruir junto ao governo jordaniano e principalmente para a população palestina residente na Jordânia, o ambiente anterior ao episódio.

$\mathrm{O}$ assassinato de Ahmed Yassin pelas forças militares israelenses em 22 de Março de 2004 foi um episódio que mostrou como as questões de segurança envolvendo palestinos, jordanianos e israelenses passaram a ficar fortemente integradas no período pós-Tratado de Paz:

A morte de Ahmed Yassin aconteceu apenas três dias após um encontro entre o rei Abdullah e o Primeiro Ministro Sharon. Esta proximidade implicava a cumplicidade da Jordânia ou pelo menos a aquiescência nesta operação que despertou fúria em toda a região (...).

(...) Milhares de jordanianos ganharam as ruas na capital e em outras grandes cidades para protestar contra o assassinato, sendo que as manifestações mais exaltadas ocorreram no campo de refugiados palestinos de Wihdat (ao leste de Amã) (...).

(...) Uma bandeira da Jordânia queimava ao lado das bandeiras dos Estados Unidos e de Israel (STEWART, 2007, p.29-30). 
Estes acontecimentos demonstram o quão sensível a Jordânia é em relação ao relacionamento bilateral entre palestinos e o Estado israelense. $\mathrm{O}$ fortalecimento da cooperação na área da segurança entre Israel e a Jordânia, com o estabelecimento de parâmetros comuns no que diz respeito ao tratamento da população palestina, no intuito de evitar ações unilaterais que produzam efeitos colaterais nos vizinhos, era uma expectativa presente quando ocorreu a formalização do Tratado de Paz.

D) O comércio: não restam dúvidas de que Oriente Médio é uma região estratégica para os interesses dos Estados Unidos. Esta afirmação soa como um clichê por pertencer ao senso comum. Assim como a associação da razão deste interesse com as grandes reservas petrolíferas da região. Desta forma, os Estados Unidos, assim como outras grandes potências econômicas, são interessados na estabilização política da região e na desestruturação de regimes antiocidentais. É importante destacar que nem toda nação do Oriente Médio é rica em recursos energéticos. Definitivamente este não é o caso de Israel e nem da Jordânia. Apesar disto, o apaziguamento das relações entre Israel e os Estados vizinhos, assim como entre Israel e os palestinos, faz parte do conjunto de preocupações das grandes potências. A profunda integração da arena política regional ficou evidenciada em acontecimentos históricos, que já demonstraram que turbulências em áreas relativamente distantes das áreas produtoras de petróleo, localizadas em Estados que não são produtores desse produto, acabaram trazendo reflexos para o preço do bem no mercado internacional. Um dos exemplos mais claros que explicitam este argumento foi a redução da produção do petróleo proposta por diversas nações árabes em retaliação ao suposto apoio norte-americano a Israel durante a Guerra de Yom Kippur (1973).

A conjuntura regional ajuda a entender as razões pelas quais os Estados Unidos são um dos maiores financiadores da paz na região, por mais contraditório que possa parecer devido aos acontecimentos recentes ligados a invasão do Iraque (2003). O Oriente Médio é o destino de $40 \%$ de toda ajuda internacional norteamericana. Recebem a ajuda dos Estados Unidos aqueles Estados que abandonam posições belicistas e contribuem para a construção da paz efetiva na região, explicitada na forma de Tratados ou compromissos assumidos. Como já foi dito, a Jordânia colheu resultados econômicos negativos a partir de sua posição de neutralidade durante a Guerra do Golfo, motivada possivelmente pelo fato do Iraque ser um dos seus principais parceiros comerciais e principalmente o seu principal fornecedor de petróleo. Os Estados Unidos suspendeu a ajuda econômica que fornecia ao reino, ao mesmo tempo em que outros Estados árabes seguiram posições semelhantes ao contribuírem para a consolidação de um quadro de recessão econômica no país. A partir da Conferência de Madrid, a Jordânia passou a reconstruir uma imagem positiva frente ao ocidente, o que trouxe ao país, em um primeiro momento, o perdão de sua dívida externa junto aos Estados Unidos, um dos seus principais credores. O Tratado de Paz entre Israel e Jordânia certamente contribuiu para o desenvolvimento do comércio entre os países signatários. Contudo, a principal diferença econômica associada à implementação do Tratado foi a melhoria do comércio bilateral entre os Estados Unidos e a Jordânia, com resultados altamente positivos para o reino.

O benefício econômico futuro figurou de forma proeminente na decisão da Jordânia de construir a paz com Israel. Primeiramente, o 
governo da Jordânia esperava receber um alívio econômico imediato e um futuro investimento estrangeiro vindo dos Estados Unidos e de outros países que apoiavam a formalização do Tratado de Paz. Além disto, relações econômicas diretas com Israel poderiam produzir novas oportunidades no comércio e um crescimento no turismo (STEWART, 2007, p.70).

Os números da ajuda externa que a Jordânia passou a receber com a formalização do Tratado dão uma dimensão exata de como os aspectos econômicos que estavam em jogo moveram o reino a implementar a paz com Israel:

\begin{abstract}
A ajuda econômica para a Jordânia através da Agência NorteAmericana para o Desenvolvimento Internacional e outros programas aumentou, assim como a ajuda militar. No ano fiscal de 1996, a Jordânia amealhou 182,7 milhões de dólares em ajuda; o que era o terceiro maior pacote de ajuda do Oriente Médio, pequeno se comparado com a ajuda recebida pelo Egito e Israel. A Jordânia tem continuado a receber grande quantidade de ajuda externa vinda dos Estados Unidos, totalizando 384,5 milhões de dólares no ano fiscal de 2004, em parte pela sua ajuda pelo apoio aos Estados Unidos durante a Guerra do Iraque, como também pelo seu papel como uma voz moderada no Oriente Médio, região que o governo dos Estados Unidos percebe como crescentemente tomada pelo extremismo. (STEWART, 2007, p.70).
\end{abstract}

Além da ajuda econômica, os Estados Unidos ajudou a implementar na Jordânia as QIZ (Qualified Industrial Zones) no ano de 1996. Essencialmente, eram áreas de livre comércio que operavam em determinadas áreas da Jordânia. Inicialmente programadas para serem implantadas em onze áreas, apenas sete permanecem em operação, sendo essenciais para alavancar o comércio com os Estados Unidos. As indústrias que operam nas QIZ têm o benefício de livre exportação para os Estados Unidos, sem restrição de quotas para a entrada no mercado norte-americano (STEWART, 2007, p.77).

Em dezembro de 2001, os Estados Unidos assinaram um Acordo de Livre Comércio com a Jordânia. Ao contrário das QIZ, que funcionavam em determinadas áreas do país, o acordo de livre comércio era válido para todo o território jordaniano, impulsionando de fato o comércio exterior do reino e transformando os Estados Unidos em seu principal parceiro comercial. As QIZ continuam funcionando concomitantemente ao acordo de livre comércio, já que a assinatura deste último eliminou tarifas e cotas de itens específicos. Desta forma, alguns industriais preferem produzir alguns itens sob a regulação das QIZ e outros sob o Acordo de Livre Comércio. Os números da exportação jordaniana saltaram de 1,47 bilhões de dólares em 1998 para 2,36 bilhões em 2003, sendo que os Estados Unidos é o principal responsável por este aumento, como pode ser percebido na tabela 3 . É importante observar o crescimento das exportações americanas após a implementação da área de livre comércio em 2001. 
As recompensas jordanianas...

TABELA 3 - Exportações da Jordânia em milhões de dólares: 1998, 2001 e 2003

\begin{tabular}{|c|c|c|c|c|c|c|}
\hline País & 1998 & $\begin{array}{l}\% \text { do } \\
\text { total }\end{array}$ & 2001 & $\begin{array}{l}\% \text { do } \\
\text { total }\end{array}$ & 2003 & $\begin{array}{l}\% \text { do } \\
\text { total }\end{array}$ \\
\hline EUA & 7 & 0,5 & 232 & 12,2 & 664 & 28,1 \\
\hline Iraque & 149 & 10,1 & 422 & 22,1 & 315 & 13,4 \\
\hline Índia & 164 & 11,2 & 204 & 10,7 & 198 & 8,4 \\
\hline $\begin{array}{l}\text { Arábia } \\
\text { Saudita }\end{array}$ & 146 & 9,9 & 134 & 7,1 & 154 & 6,5 \\
\hline Israel & 34 & 2,3 & 102 & 5,4 & 96 & 4,1 \\
\hline E.A.U & 81 & 5,5 & 83 & 4,4 & 92 & 3,9 \\
\hline Síria & 21 & 1,5 & 36 & 1,9 & 90 & 3,8 \\
\hline Líbano & 42 & 2,9 & 39 & 2 & 45 & 1,9 \\
\hline $\begin{array}{l}\text { Outros } \\
\text { países } \\
\text { árabes }\end{array}$ & 657 & 44,6 & 245 & 12,9 & 276 & 11,7 \\
\hline $\begin{array}{l}\text { Outros } \\
\text { países }\end{array}$ & 169 & 11,5 & 407 & 21,4 & 427 & 18,1 \\
\hline Total & 1475 & & 1907 & & 2362 & \\
\hline
\end{tabular}

Os benefícios para a Jordânia advindos do aumento das exportações para os Estados Unidos estão diretamente associados ao posicionamento do reino como um promotor da paz regional, posição que notadamente foi consolidada com a assinatura do Tratado de Paz com Israel. Em termos relativos, a Jordânia é hoje um país mais desenvolvido do que era antes da assinatura do Tratado em 1994. Obteve ao longo dos anos 1990 uma taxa de crescimento econômico de 6\% ao ano. Apesar da Guerra do Iraque ter diminuído o crescimento econômico a uma taxa de 3,2\% em 2003 , o país voltou a crescer em 2004, exibindo uma taxa de $5,5 \%$.

A Jordânia é servida por somente um porto, o que é explicado em parte pela sua pequena costa. Este porto em Ácaba fica no extremo sul do país, distante das QIZ (apesar da cidade de Ácaba possuir uma destas zonas industriais), o que explica o fato da maior parte dos produtos produzidos nestas áreas serem exportados pelo porto de Haifa, em Israel, que é bem mais próximo. Com o aumento das exportações para os Estados Unidos, a dependência da Jordânia em relação ao porto de Haifa também aumenta.

Antes da formalização do Tratado de Paz, não havia a opção pela exportação através do porto israelense de Haifa, uma vez que Jordânia e Israel não possuíam relações diplomáticas. Ao mesmo tempo, o comércio externo da Jordânia estava amplamente orientado para os países árabes. É plausível admitir que a assinatura do Tratado colaborou para transformar o comércio da Jordânia, basicamente regional, em intercontinental. A crescente dependência do porto de Haifa cria outra disputa entre Israel e Jordânia: a desburocratização. Por medidas de segurança, 
caminhões jordanianos que entram no território israelense passam por um apurado processo de revista, o que atrasa as exportações.
A entrada de motoristas jordanianos dentro do território israelense é também problemática, a partir de questões de segurança $e$ administrativas. A partir da perspectiva israelense, a entrada de motoristas jordanianos representa um grande risco para a segurança; é geralmente difícil para os agentes de exportação jordanianos conseguir visto para os seus motoristas, sendo que algumas companhias precisam esperar até 3 anos para tanto. Até mesmo com o visto, os motoristas precisam esperar muito tempo nas áreas de espera sem comida e bebida enquanto a fiscalização é executada (...)
(...) Caminhões jordanianos geralmente são reprovados na inspecção baseada nos padrões israelenses de segurança, apesar dos exportadores jordanianos argumentarem que Israel não deixa claro quais padrões são esses, assim como as listas que são apresentadas aos motoristas a respeito de violações de segurança não serem a mesma em hebraico e árabe, o que reforça a confusão (STEWART, 2007, p.86).

A partir do exposto, é plausível admitir que as dificuldades impostas pela burocracia israelense servem para mostrar a relevância do porto de Haifa para os exportadores jordanianos, pois, é razoável pensar que, mediante estas dificuldades, estes exportadores optem pelo distante porto de Ácaba, no sul do país, o que não acontece.

\section{CONSIDERAÇÕES FINAIS}

Como foi problematizado na introdução, em um mundo marcado pelos prodígios da comunicação e dos transportes, que encurtaram as distâncias e permitiram maior integração entre as nações, forças cooperativas podem ser prioritárias frente às forças conflitivas. Apesar de experimentarem o dissabor de um histórico marcado pelo conflito militar, Jordânia e Israel assinaram um Tratado de Paz em 1994. O artigo versou sobre a ótica jordaniana dos benefícios advindos do tratado em questão. O comércio, o desenvolvimento do setor hoteleiro, a questão dos palestinos e o compartilhamento das águas transnacionais da Bacia do rio Jordão convidaram o reino Hashemita à paz, por oferecer recompensas que tornaram a posição conflitiva e de rejeição à existência do estado de Israel muito custosa. Se por um lado as sanções econômicas surtem poucos efeitos políticos no isolado Myanmar, como salienta Joseph Nye Jr (2002), por outro, o custo do isolamento em um mundo integrado é muito alto.

O Tratado de Paz entre a Jordânia e Israel encontra no caminho de sua consolidação elementos de um mundo de conexões fortíssimas que colaboram para a resolução das diferenças, mesmo que históricas, entre Estados outrora rivais. Ainda que posições realistas mais ortodoxas acreditem que os Tratados são pedaços de papel que são cumpridos apenas até o momento em que convier a um dos signatários, existem mudanças na contemporaneidade profundas demais para justificar o abandono da cooperação e o refúgio do isolamento. É mais coerente pensar, nas características atuais das Relações Internacionais, que os conflitos passam a existir como instrumentos de barganha para construir a cooperação que Estudos Geográficos, Rio Claro, 15(2): p-p, jul./dez. 2017 (ISSN 1678-698X) 
se deseja alcançar. Este tem sido o tom que paulatinamente ecoa pelos nossos ouvidos no período pós-Guerra Fria. Apesar da teoria de Huntington (1996) ter conquistado corações e mentes ao mesmo tempo em que foi duramente questionada, é possível considerar o papel da cultura como um elemento de interferência nas relações internacionais. Contudo, a cultura parece guiar a violência em um outro plano diferente daquele povoado pelos Estados.

Como os elementos de integração que sustentam a Teoria da Interdependência Complexa não se apresentam absolutos, estanques, há de se considerar uma dinâmica que os intensifica paulatinamente, tornando, pelo menos em parte, os pressupostos de Keohane e Nye Jr. (2012) como instrumentos úteis de interpretação do mundo no nosso tempo.

\section{REFERÊNCIAS BIBLIOGRÁFICAS}

FUKUYAMA, Francis. O Fim da história. Rio de Janeiro: Rocco, 1992, 489p.

HARVEY, David. A Condição Pós-Moderna. São Paulo: Edições Loyola, 2004, $349 p$.

HUNTINGTON, Samuel. O choque das civilizações e a recomposição da ordem mundial. Rio de Janeiro: Objetiva, 1997, 455p.

JAGERSKOG, Anders. Why states cooperate over shared water: The water negotiations in the Jordan River Basin. Linköping: Linköping University, 2003, 198p.

KEOHANE, Robert O; NYE JR., Joseph S. Power and interdependence: world politics in transition. Boston: Little, $4^{\text {th }}$ Edition, 2012, 330p

LOWI, Miriam R. Water and Power. The politics of a scarce resource in the Jordan River Basin. New York: Cambridge University Press, 1995, 297p.

NYE JR, Joseph S. The paradox of American power. New York: Oxford University Press, 2002, 222p.

OHMAE, Kenichi. O fim do Estado-Nação. Rio de Janeiro: Editora Campus, 1999, 214p.

ROSECRANCE, Richard. The Rise of the Trading State: Commerce and Conquest in The Modern World. New York: Basic Books, 1986, 268p.

SOSLAND, Jeffrey K. Cooperating Rivals: The riparian politics of the Jordan

River Basin. New York: State University of New York, 2007.

STEWART, Dona. Good neighbourly relations. Jordan, Israel and the 1994-2004 peace process. New York: Tauris Academic Studies, 2007. 215p.

TSEBELIS, George. Jogos Ocultos: Escolha racional no campo da política comparada. São Paulo: Edusp, 1998, 249p. 